\title{
FUNCTIONAL MODIFICATION OF POLY VINYL ALCOHOL/ACRYLIC ACID HYDROGELS PREPARED BY $\Gamma$ - RADIATION THROUGH SOME AMINE COMPOUNDS
}

\author{
BY \\ Hala M. Aly*a , H. L. Abd El-Mohdy ${ }^{\mathrm{b}}$ \\ FROM \\ ${ }^{a}$ Department of Chemistry, Faculty of Science (Girls), Al-Azhar University, Nasr City, \\ Cairo, Egypt \\ ${ }^{b}$ National Center for Radiation Research and Technology, P.O. Box 29, Nasr City, \\ Cairo, Egypt
}

\begin{abstract}
Radiation induced-poly vinyl alcohol/acrylic acid (PVA/AAc) hydrogels were modified through condensation reaction with various aliphatic and aromatic amines to form amine-treated polymers. The amine compounds are 2-amino-3-(4-hydroxyphenyl) propanoic acid (P1), propane-1,2-diamine (P2), 4-amino-1,5-dimethyl-2-phenyl-1,2dihydropyrazol-3-one (4-aminoantipyrine) (P3), 2-aminothiazol (P4), 4-amino- $N$-(1phenyl-1H-pyrazol-5-yl) benzene sulfonamide (P5) and 4-amino- $N$-(4-methoxy-1,2,5thiadiazol-3-yl) benzene sulfonamide (P6). The degree of swelling of amine-modified polymers increased with increasing AAc contents in the PVA/AAc copolymer and lowered irradiation doses, reaching its maximum at PVA: AAc composition; 50:50 $\mathrm{wt} \%$. The characterization of all synthesized polymeric compounds was carried out by using IR, NMR and UV spectral analysis, in addition to thermal studies which predicted by thermal gravimetric analysis (TGA) and differential scanning calorimetry (DSC). Thermal studies display that the amine-treated polymers have more thermal stability than untreated ones. All the newly synthesized polymeric compounds were evaluated for their antibacterial and antifungal activities in vitro against two Gram-positive bacteria and two Gram negative bacteria as well as two fungi by the disc diffusion method. In general, the newly synthesized polymeric compounds exhibited higher promising biological activities and can be used in medical applications.
\end{abstract}

Keywords: Functional modification; polyvinyl alcohol; acrylic acid; amine; hydrogels; $\gamma$-radiation

\section{Introduction}

Hydrogels consist of a hydrophilic polymer that forms a three-dimensional network, which contains a lot of water. They are one of the most promising materials for biomedical applications and have several advantages for wound dressing, contact lenses, drug delivery systems, etc. because of their biocompatibility with blood, body fluids, and tissue (Das et al., 2012; Benamer et al., 2006; Jayachandran et al., 2014). Hydrogels must sustain their physical strength and contain $>75 \%$ water. Their water adsorption ability is due to hydration, which is related to chemical groups (such as - 
$\mathrm{COOH}, \mathrm{CONH}_{2},-\mathrm{CONH}-$, and $\mathrm{SO}_{3} \mathrm{H}$ ); capillary effect, and osmotic pressure (Abd ElMohdy and Abd El-Rehim 2008). These hydrogels also undergo volume change, do not dissolve, and have stable strength, properties that are caused by ionic, hydrophobic, and van der Waals forces. However, the effects of these forces are small; and covalent bonding is prevalent (Aziz et al., 2012; Zhang et al., 2005). In fact, hydrogels have been prepared by chemical methods for a long time. However, in recent years, irradiation techniques to produce hydrogels are being used increasingly around the world. This technology is convenient because the physical properties can be manipulated easily by irradiation (Abd El-Mohdy and Ghanem 2009).

Synthesis of functional polymeric particles and polymers for surface functionalization as well as bio-compatible and bio-degradable polymers is a research focus providing links to the research areas such as hybrid structures and bio-related materials. More research has examined end-functional polymers as a method of preparation of various copolymers (Pernot et al., 2002; Yin et al., 2003). Reactions of functional polymers can most easily be studied if the polymer structure is well-defined, with fixed functional group position and molecular weight, and low polydispersity. Chemical modification of polymers has widespread applications, as the obtained functionalized polymers acquire the reactivity of the introduced functionality while keeping the main features of the base polymeric matrix (Izaoumen et al., 2005). Hence, many functional polymers have been prepared through the reaction of polymers with different chemically reactive species. Functionalization can also be achieved through physical blending of some organic compounds such as amine compounds (Sarhan et al., 2002; Abdel-Bary et al., 1997). However, hydrogels with basic groups, such as amine groups, expand and shrink at lower and higher $\mathrm{pH}$ values (Abd El-Mohdy 2007; Abd El-Mohdy et al., 2006; Abd El-Mohdy 2012).

Therefore, the present study is an attempt, to study the functional modification of poly vinyl alcohol/acrylic acid hydrogels prepared by $\gamma$-radiation through some amine compounds such as L-tyrosine, 1,2-diaminopropane, 2-aminoantipyrine, 4-amino- $N$-(1phenyl- $1 H$-pyrazol-5-yl) benzene sulfonamide, 4-amino- $N$-(4-methoxy-1,2,5-thiadiazol3-yl)benzene sulfonamide and thiazol-2-amine. The prepared PVA/AAc hydrogels and amine-modified ones were characterized by FTIR, ${ }^{1} \mathrm{H}$ NMR TGA, DSC, SEM and swelling behavior.

\section{Experimental}

\section{Materials}

Poly vinyl alcohol and acrylic acid (purity 99\%), 2-amino-3-(4-hydroxyphenyl) propanoic acid, propane-1,2-diamine, 4-amino-1,5-dimethyl-2-phenyl-1,2dihydropyrazol-3-one (4-aminoantipyrine), 2-aminothiazol, 4-amino- $\mathrm{N}$-(1-phenyl-1 $\mathrm{H}$ pyrazol-5-yl) benzene sulfonamide and 4-amino- $N$-(4-methoxy-1,2,5-thiadiazol-3-yl) benzene sulfonamide (Merck, Germany) were used as received, the chemical structures are shown in Figure 1. 


\section{Hydrogel preparation}

Hydrogel was obtained by ionizing irradiation process of gamma source of 4.25 $\mathrm{kGy} / \mathrm{h}$ dose rate. Various PVA : AAc ratios of $100: 0.0,90: 10,80: 20,60: 40$ and 50 : $50 \mathrm{wt} \%$ were prepared. The mixture was stirred at room temperature for 30 mins.

\section{Chemical modification of PVA/AAc hydrogels}

Different amine compounds were used as starting point for the introduction of new functional groups via nucleophilic addition of amino groups containing chemical compounds such as amines to produce the corresponding derivatives. The chemical modification was carried out by refluxing $1 \mathrm{~g}$ of PVA/AAc hydrogels with PVA : AAc ratio; $50: 50 \mathrm{wt} \%$ and irradiation dose; $30 \mathrm{kGy}$ with an appropriate amount of amine in $\mathrm{EtOH} / \mathrm{EtONa}$ as a catalyst with few drops of (DMF) at $80^{\circ} \mathrm{C}$ for $72 \mathrm{~h}$. The treated hydrogels were thoroughly washed in hot DMF followed by ethyl alcohol, dried at $60^{\circ} \mathrm{C}$ for $6 \mathrm{~h}$ and kept in dry place.

\section{FT-IR Spectroscopy}

Analysis by Infra-Red Spectroscopy was carried out by using Mattson 1000, Unicam, Cambridge, England in the range from $400-4000 \mathrm{~cm}^{-1}$.

\section{Swelling measurement}

Dried hydrogel discs (0.3-0.4 mm thickness, $4 \mathrm{~mm}$ diameter) were left to swell in distilled water for $24 \mathrm{~h}$. Swollen gel was removed from the swelling medium at regular time intervals and superficially dried with filter paper, and then it was weighed and placed in the same bath. The measurement was continued until a constant weight.

$$
\text { Swelling } \%=\left(\mathrm{W}_{\mathrm{s}}-\mathrm{W}_{\mathrm{d}} / \mathrm{W}_{\mathrm{d}}\right) \times 100
$$

Where, $\mathrm{W}_{\mathrm{s}}$ and $\mathrm{W}_{\mathrm{d}}$ represent the weights of swollen and dry samples, respectively.

\section{Thermal gravimetric analysis (TGA)}

Perkin Elmar TGA system under Nitrogen atmosphere $10 \mathrm{~mL} / \mathrm{min}$ was used. The temperature range was from ambient temperature to $600^{\circ} \mathrm{C}$.

\section{Differential scanning calorimetry (DSC)}

Differential scanning calorimetry measurements were performed with a PerkinElmer model DSC-7. A specimen $(\approx 5 \mathrm{mg})$ of the sample was used for DSC measurements. Indium and zinc standards were used to calibrate the temperature and thermal scale. The measurements were carried out in a $\mathrm{N}_{2}$ atmosphere from 20 to $220^{\circ} \mathrm{C}$ at a heating rate of $10^{\circ} \mathrm{C} / \mathrm{min}$.

\section{pH Measurements}

The $\mathrm{pH}$ of solutions was determined by using a Jenway $3310 \mathrm{pH}$ Meter.

\section{Scanning electron microscopy (SEM)}

The lyophilized dried hydrogels were examined with a Jeol JSM-5400 SEM microscope. The surfaces of the polymers were sputter coated with gold for 3 min. 


\section{Antimicrobial assay}

Four bacteria and four fungi were used as test microorganisms in this study. Test fungi included, Aspergillus fumigatus, Geotrichum candidum, Candida albicans and Syncephalastrum racemosum on Sabourad dextrose agar plates. Test bacteria included, Staphylococcus aureus and Bacillus subtilis (as gram positive bacteria) while Pseudomonas aeruginoca and Escherichia coli (as gram negative bacteria). All strains were supplemented by the Regional Center for Mycology and Biotechnology, Al-Azhar University, Cairo, Egypt. The medium used for growing bacteria were universal nutrient agar while Sabouraud and/or yeast malt extract agar was used for fungi. Antimicrobial activity was determined by agar well-diffusion method. Briefly, agar plates were seeded with test microorganisms and kept for $30 \mathrm{~min}$ until medium solidified. Circular pieces of about $5 \mathrm{~mm}$ diameters of test hydrogel samples were added. Plates were kept for $2 \mathrm{hs}$ at $4{ }^{\circ} \mathrm{C}$ prior to incubating at appropriate temperature for bacteria or fungi. Plates were examined on daily bases for development of growth inhibition zones around the loaded hydrogels.

\section{Results and discussion}

Scheme 1 shows the radiation-induced crosslinked co-polymerization of PVA and AAc in addition to the interaction between PVA/AAc and different amine compounds for modification of their various properties.

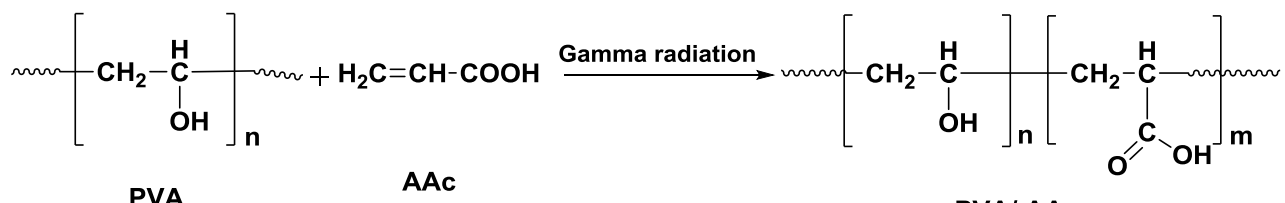

PVA/ AAC
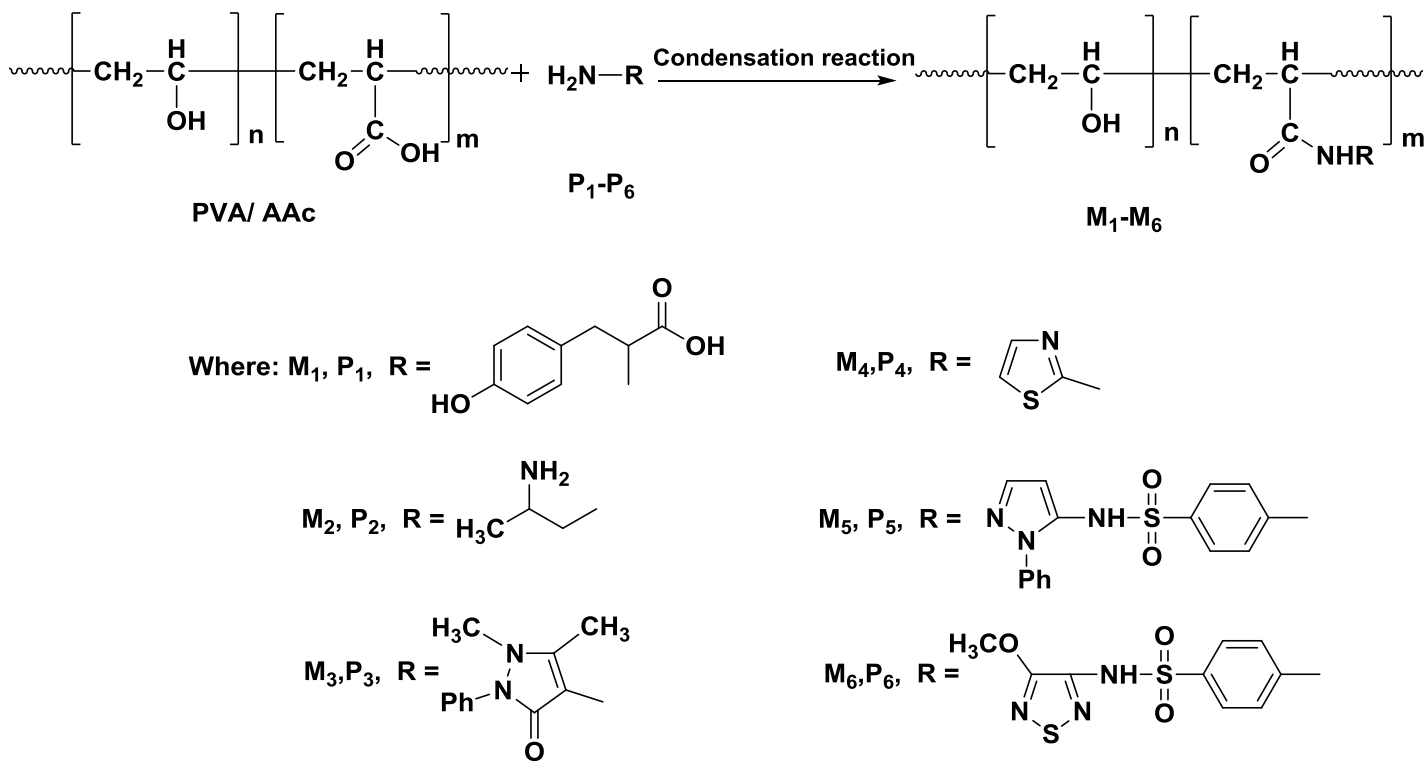

Scheme 1. Synthesis of radiation-induced crosslinked co-polymerization of PVA/AAc and its interaction with different amine compounds. 


\section{Gel fraction}

The degree of crosslinking of polymers can be studied by an estimation of the mass percentage of the gel fraction. A typical dependence of gel fraction on the PVA/AAc compositions and irradiation doses was given in Fig.1. It can be seen that the gel fraction increased with increasing irradiation dose and interaction between PVA and AAc. It is increased with AAc content in PVA/AAc hydrogel, the composition at 70/30 ratios gave a maximum gel content at different irradiation doses, whereas a further increase in AAc decreased the gel content. The high gel fraction of PVA/AAc hydrogels occurred due to higher degree of cross-linking of the polymer networks at high irradiation doses.

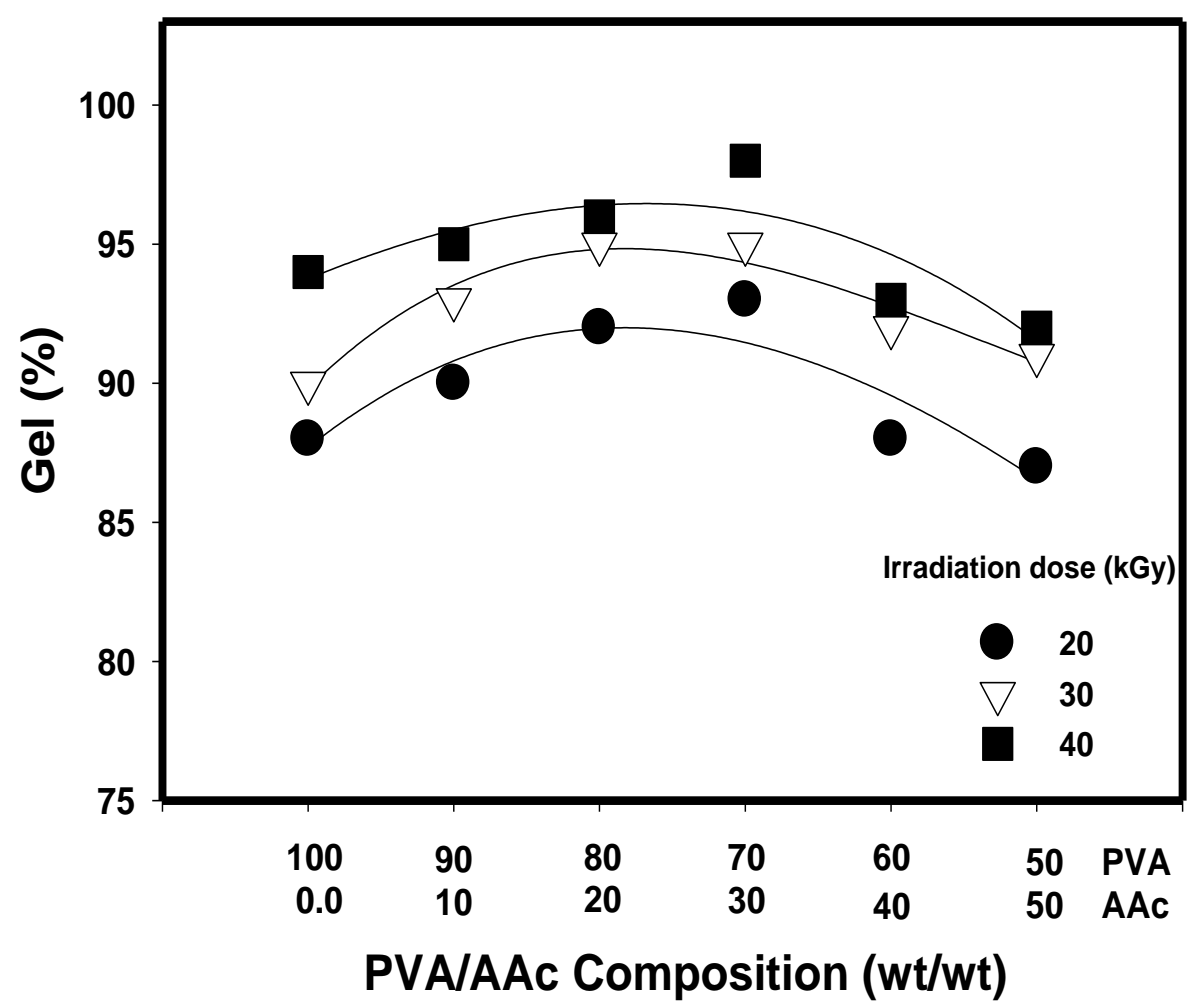

Figure 1. Effect of various PVA:AAc compositions on the gel content of PVA/AAc hydrogels at different irradiation doses.

\section{FT-IR spectroscopy}

FTIR spectroscopy and ${ }^{1} \mathrm{H}$ NMR spectra were carried out here to confirm the chemical structure and interactions products of PVA/AAc polymeric networks with 
different amine compounds. FTIR spectra of PVA/AAc, amine compounds (P1-P6) and amines-modified PVA/AAc hydrogels (M1-M6) are recorded in Figures 2-7. FTIR spectrum of PVA/AAc copolymer showed characteristic bands of both acrylic acid repeating units and PVA unit which appeared at shifted positions as shown in Figure 2a. A very wide broad absorption band was observed within the range $3050-3600 \mathrm{~cm}^{-1}$ which may be explained due to $\mathrm{O}-\mathrm{H}$ stretching $\mathrm{H}$-bonding between the carboxylic groups of AAc and the hydroxyl groups of PVA. A very broad band corresponding to carboxyl groups of acrylic acid has stretched frequency in the region $3000-2500 \mathrm{~cm}^{-1}$. It shows a broad absorption band observed at $1760 \mathrm{~cm}^{-1}$ due to $\mathrm{C}=\mathrm{O}$ stretching of carboxylic acid association in PVA/AAc hydrogel. O-H out of plane bend observed near $860 \mathrm{~cm}^{-1}$. N-H out of a plane band, observed near $800 \mathrm{~cm}^{-1}$. There is a sharp band at about $1720 \mathrm{~cm}^{-1}$ characteristic of the carbonyl group of acrylic acid. In addition to this, other characteristic bands related to $\mathrm{OH}$ group of the carboxyl group are observed at 1454 and $1119 \mathrm{~cm}^{-1}$ indicating the incorporation of acrylic acid units in the copolymer chains. This is supported with ${ }^{1} \mathrm{H}$ NMR spectra, there are disappearance of both the signals which related to $\mathrm{OH}$ group of the carboxyl group for the unit of acrylic acid in PVA/AAc hydrogel units at $\delta 10.7$ ppm and the signals characteristic for $\mathrm{NH}_{2}$ groups for all amine units.

FTIR spectrum of 2-amino-3-(4-hydroxyphenyl) propanoic acid (P1) was shown in Figure 2b. It showed a broad band in the range $3600-3200 \mathrm{~cm}^{-1}$, which derived from $\mathrm{N}-\mathrm{H}$ and $-\mathrm{OH}$ stretching vibrations. A very broad band corresponding to carboxyl groups has stretched frequency in the region $3000-2500 \mathrm{~cm}^{-1}$. The sharp band at 2910 $\mathrm{cm}^{-1}$ is due to the stretching vibration of backbone aliphatic $\mathrm{C}-\mathrm{H}$. The strong absorption peak at $1130 \mathrm{~cm}^{-1}$ has been assigned to the $\mathrm{C}-\mathrm{O}$ in stretching mode and the bands observed at $1355 \mathrm{~cm}^{-1}$ have been attributed to combination frequencies of $\mathrm{CH}$ $\mathrm{OH}$. The $\mathrm{C}=\mathrm{C}$ aromatic stretches appear in a pair of peaks, one at $670 \mathrm{~cm}^{-1}$ and the other one at $1475 \mathrm{~cm}^{-1}$. The band observed at $1438 \mathrm{~cm}^{-1}$ can be assigned to the $\mathrm{C}-\mathrm{N}$ stretching vibrations of the amines (Yin et al., 2003). FTIR spectrum of PVA/AAc/P1 (M1) was shown in Figure 2c. There is a shift in absorption bands of $\mathrm{C}=\mathrm{O}$ stretching of carboxylic acid to lower value which observed at $1748 \mathrm{~cm}^{-1}$. The ${ }^{1} \mathrm{H}$ NMR spectrum $\left(\mathrm{DMSO}_{\mathrm{d}}, 300 \mathrm{MHz}\right)$ of M1 was confirmed by the signals at $\delta 3.1,4.8 \mathrm{ppm}$. These were attributed to the methylene $\left(-\mathrm{CH}_{2}^{-}\right)$adjacent to the phenyl ring and methine (-CH-) 
protons in the L-Tyrosine moiety. According to chemical shift rule, other protons in amine moiety which characteristic to phenyl group, imino, hydroxyl and carboxylic groups were appeared at $\delta 6.7-6.9,8.4,9.1$ and $12.8 \mathrm{ppm}$, respectively. In addition to, the presence of characteristic signals at $\delta 1.2,1.6 \mathrm{ppm}$ for the two methylene $\left(-\mathrm{CH}_{2}-\right)$ protons, 2.3, $3.7 \mathrm{ppm}$ for two methine (-CH-) protons and $4.4 \mathrm{ppm}$ which assigned the $\mathrm{OH}$ group in PVA/AAc hydrogel units.

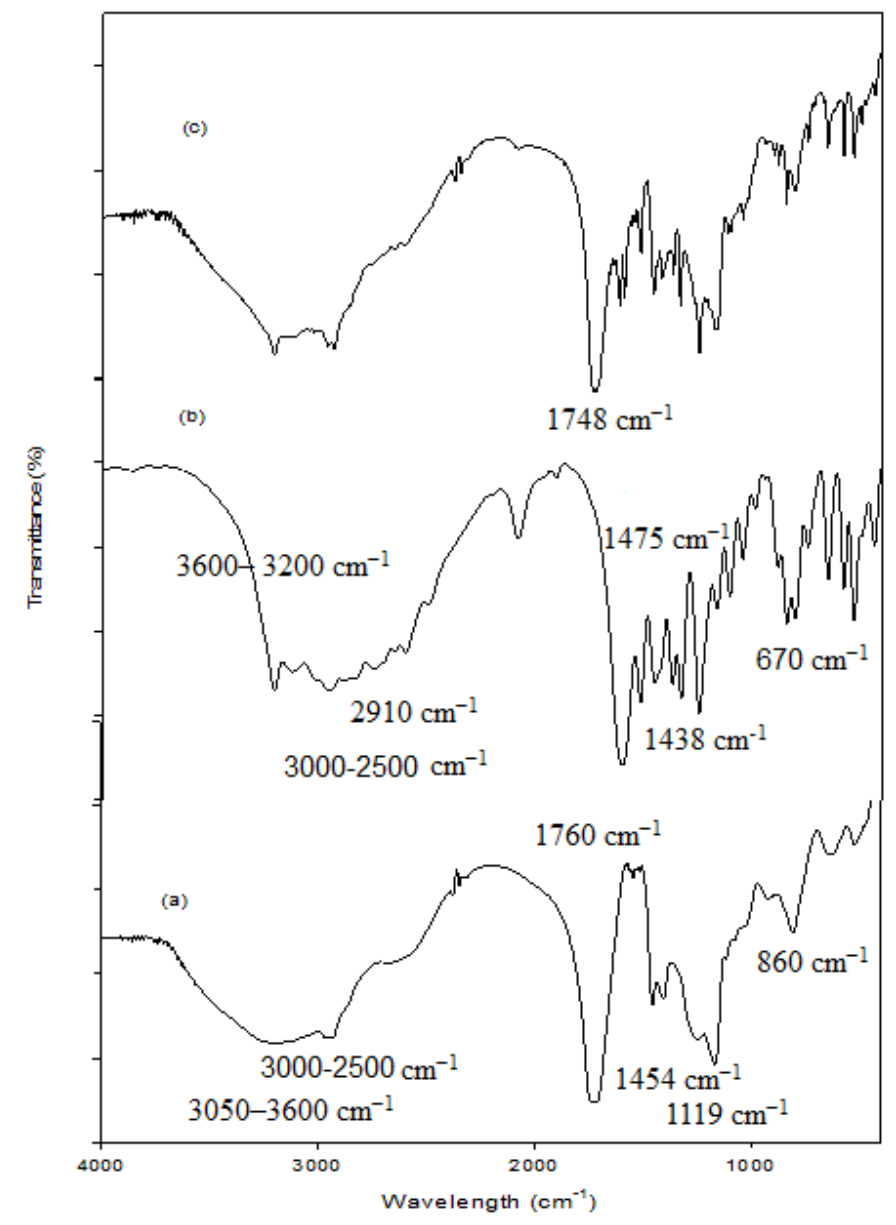

Figure 2. FT-IR spectra of (a) PVA/AAc hydrogel, (b) P1 and (c) M1.

FTIR spectrum of propane-1,2-diamine (P2) was shown in Figure 3b. The sharp band at $2910 \mathrm{~cm}^{-1}$ is due to the stretching vibration of backbone aliphatic C-H. N-H stretching broad bands appeared at $3300 \mathrm{~cm}^{-1}$. C-N stretch occurred at $1250 \mathrm{~cm}^{-1}$. The band observed at $1438 \mathrm{~cm}^{-1}$ can be assigned to the $\mathrm{C}-\mathrm{N}$ stretching vibrations of the amines (Sanghi and Verma 2009).

FTIR spectrum of PVA/AAc/P2 (M2) was shown in Figure 3c. There is a shift in absorption band of $\mathrm{N}-\mathrm{H}$ bending to lower value in addition to reduction of the band broadening. The ${ }^{1} \mathrm{H}$ NMR spectrum (DMSO- $\mathrm{d}_{6}, 300 \mathrm{MHz}$ ) of $\mathbf{M} 2$ was established by the absence of the signal for carboxylic group in PVA/AAc copolymer and presence the protons of methyl, amine $\left(-\mathrm{NH}_{2}\right)$, methane $\left(-\mathrm{CHNH}_{2}-\right)$, methylene $\left(-\mathrm{CH}_{2} \mathrm{NH}-\right)$, and 
amido (-NH) at $\delta 1.1,1.5,3.2,3.4$ and $8.1 \mathrm{ppm}$. Also, presence the characteristic signals at $\delta 1.3,1.7 \mathrm{ppm}$ for the two methylene $\left(-\mathrm{CH}_{2}-\right)$ protons, and $2.2,3.7 \mathrm{ppm}$ for two methine (- $\mathrm{CH}-)$ protons and $4.3 \mathrm{ppm}$ which assigned the $\mathrm{OH}$ group.

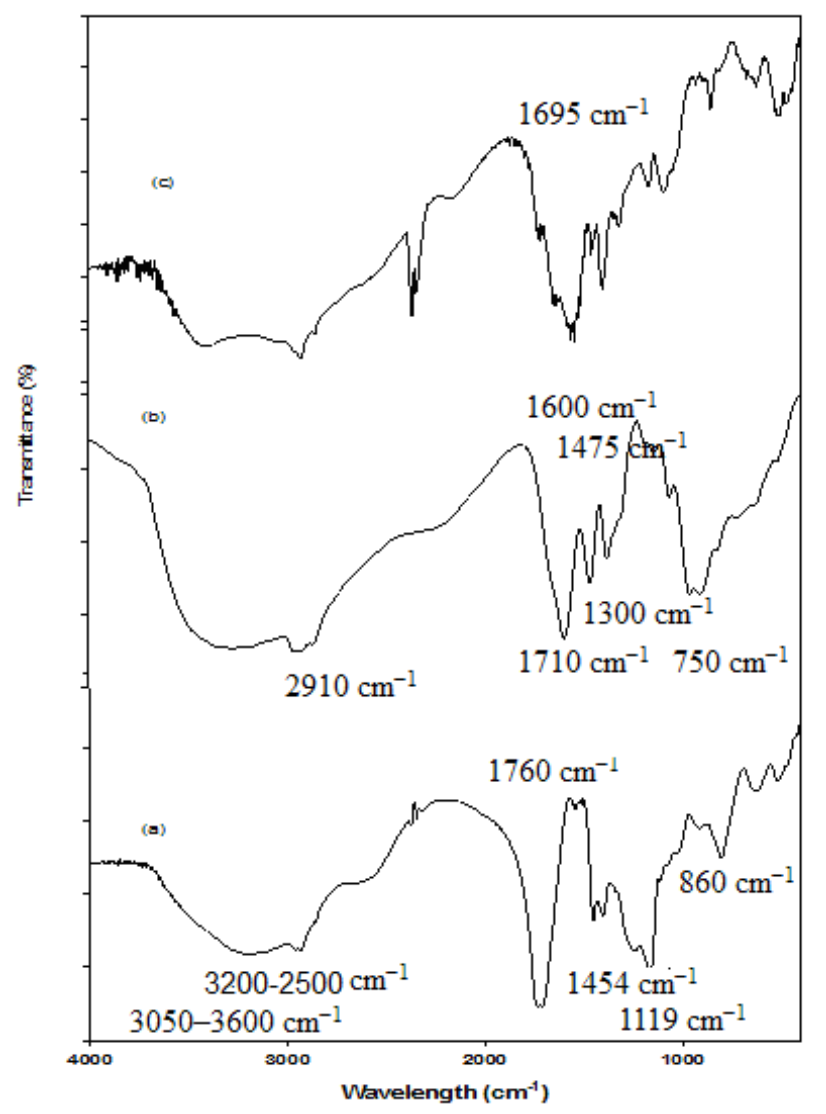

Figure 3. FT-IR spectra of (a) PVA/AAc hydrogel, (b) P2 and (c) M2.

FTIR spectrum of 4-aminoantipyrine (P3) was shown in Figure 4b. The sharp band at $2910 \mathrm{~cm}^{-1}$ is due to the stretching vibration of backbone aliphatic $\mathrm{C}-\mathrm{H}$. The $\mathrm{C}=\mathrm{C}$ aromatic stretches appear in a pair of peaks, one at $1600 \mathrm{~cm}^{-1}$ and the other one at $1475 \mathrm{~cm}^{-1}$. It shows a broad absorption band observed at $1670 \mathrm{~cm}^{-1}$ due to $\mathrm{C}=\mathrm{O}$ stretching of amide groups. N-H stretching broad band appeared at $3340 \mathrm{~cm}^{-1}$. C-N stretch occurs at $1300 \mathrm{~cm}^{-1}$. FTIR spectrum of PVA/AAc/P3 (M3) was shown in Figure 4c. There is a shift in absorption band of $\mathrm{C}=\mathrm{O}$ stretching of carboxylic acid to lower value which observed at $1695 \mathrm{~cm}^{-1}$. The new synthetic polymer M3 was supported by ${ }^{1} \mathrm{H}$ NMR spectrum (DMSO- $\mathrm{d}_{6}, 300 \mathrm{MHz}$ ) in which signals of $\mathrm{NH}_{2}$ protons in the antipyrine moiety, carboxylic group in PVA/AAc copolymer disappeared and presence the signal assign amido proton at $\delta 9.3 \mathrm{ppm}$. Also, $1.3,1.6$ for $\left(2-\mathrm{CH}_{2}\right), 2.2\left(-\mathrm{CH}_{3}\right), 2.4$, $3.6(2-\mathrm{CH}), 3.0\left(-\mathrm{NCH}_{3}\right), 4.4(\mathrm{OH}), 7.1-7.5 \mathrm{ppm}(\mathrm{m}, \mathrm{Ar}-\mathrm{H})$. 


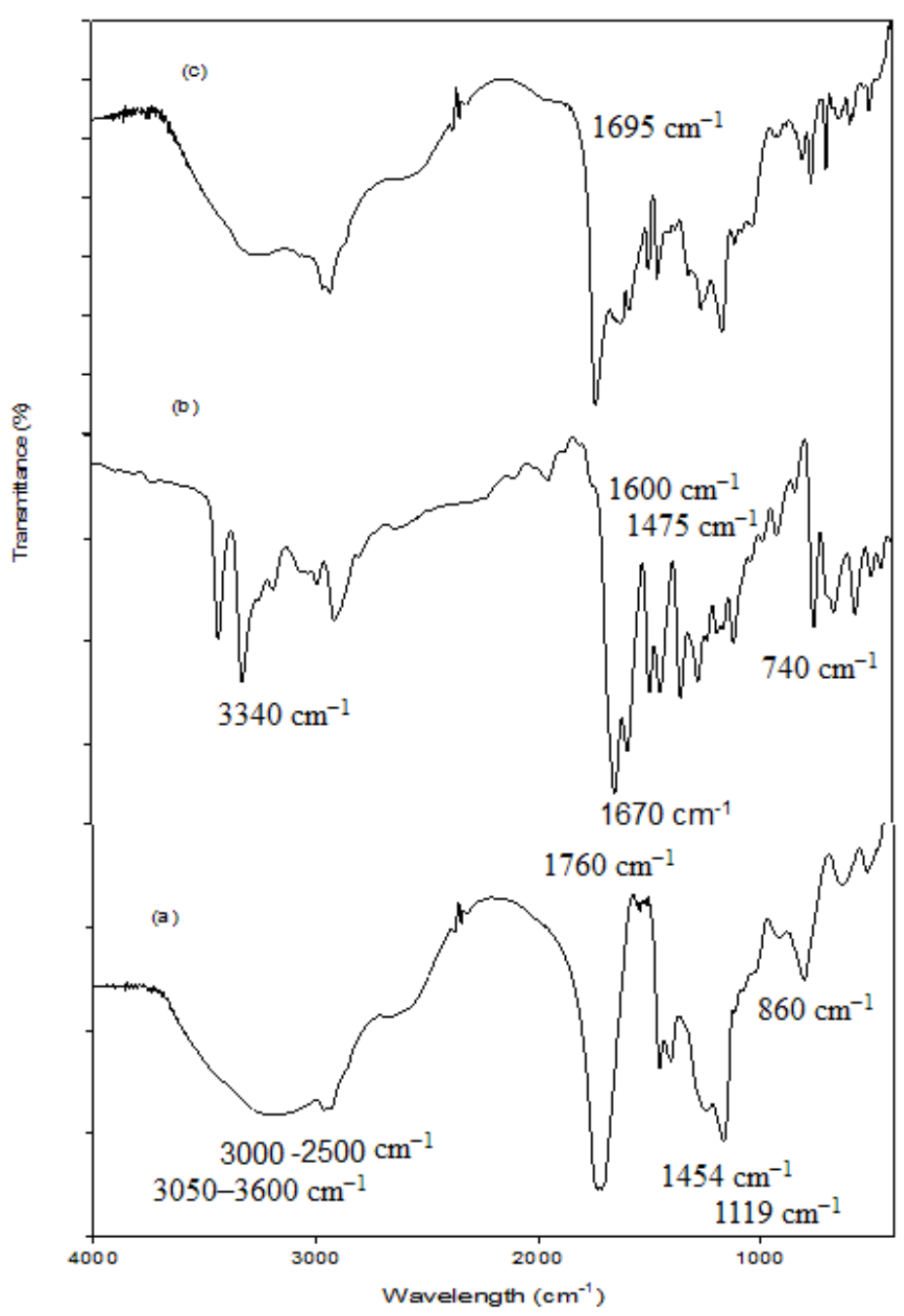

Figure 4. FT-IR spectra of (a) PVA/AAc hydrogel, (b) P3 and (c) M3.

FTIR spectrum of 2-aminothiazol (P4) was shown in Figure 5b. The sharp band at $2910 \mathrm{~cm}^{-1}$ is due to the stretching vibration of backbone aliphatic $\mathrm{C}-\mathrm{H}$. The $\mathrm{C}=\mathrm{C}$ stretches appear in a pair of beaks, one at $1600 \mathrm{~cm}^{-1}$ and the other one at $1475 \mathrm{~cm}^{-1}$. N$\mathrm{H}$ stretching broad bands appeared at $3340 \mathrm{~cm}^{-1}$ whereas, N-H out of a plane band observed near $740 \mathrm{~cm}^{-1}$. C-N stretch occurred at $1250 \mathrm{~cm}^{-1}$.

FTIR spectrum of PVA/AAc/P4 (M4) was shown in Figure 5c. There is a shift in absorption band of $\mathrm{C}=\mathrm{O}$ stretching of carboxylic acid to lower value which observed at $1695 \mathrm{~cm}^{-1}$. The ${ }^{1} \mathrm{H}$ NMR spectrum of M4 in DMSO- $d_{6}$ revealed the presence signals at $\delta=1.3$ and $1.6 \mathrm{ppm}$ characteristic for two methylene $\left(-\mathrm{CH}_{2}-\right)$ proton groups with two signals at $\delta 2.4,3.7 \mathrm{ppm}$ characteristic for methine (-CH-) protons and $4.3 \mathrm{ppm}$ for $\mathrm{OH}$ group of PVA/AAc copolymer moiety, in addition to the signals at $\delta 7.1,7.4$ and 12.6 ppm attributable to thiazole $-\mathrm{H}$ and $\mathrm{NH}$ protons. 


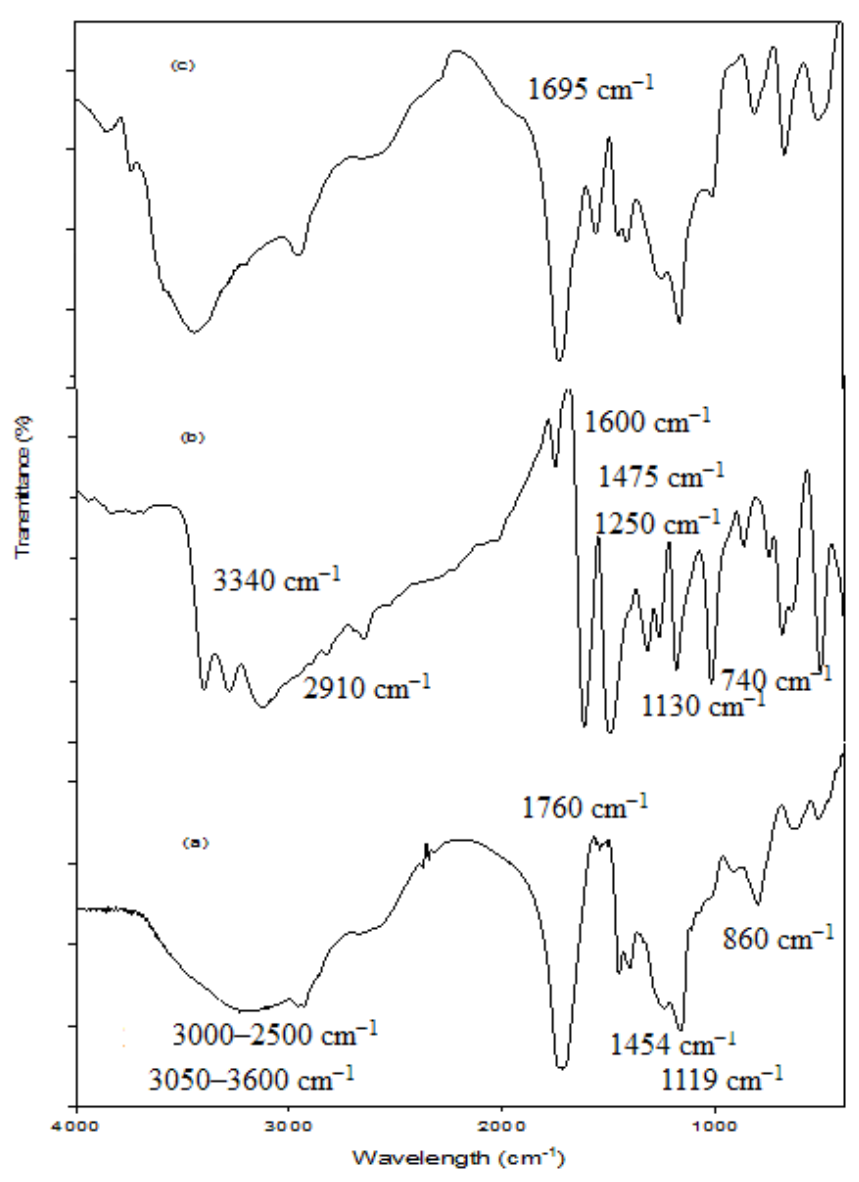

Figure 5. FT-IR spectra of (a) PVA/AAc hydrogel, (b) P4 and (c) M4.

FTIR spectrum of 4-amino- $N$-(1-phenyl-1H -pyrazol-5-yl)benzene sulfonamide (P5) was shown in Figure 6. A very broad band corresponding to carboxyl groups has stretched frequency in the region $3000-2500 \mathrm{~cm}^{-1}$. The sharp band at $2910 \mathrm{~cm}^{-1}$ is due to the stretching vibration of backbone aliphatic $\mathrm{C}-\mathrm{H}$. The strong absorption peak at $1130 \mathrm{~cm}^{-1}$ has been assigned to the $\mathrm{C}-\mathrm{O}$ in stretching mode and the bands observed at $1355 \mathrm{~cm}^{-1}$ have been attributed to combination frequencies of $\mathrm{CH}-\mathrm{OH}$. The $\mathrm{C}=\mathrm{C}$ aromatic stretches appear in a pair of beaks, one at $1600 \mathrm{~cm}^{-1}$ and the other one at 1475 $\mathrm{cm}^{-1}$. N-H stretching appeared at $3300 \mathrm{~cm}^{-1}$. C-N stretch occurred at $1300 \mathrm{~cm}^{-1}$ whereas, $\mathrm{S}=\mathrm{O}$ stretching appeared at $1400 \mathrm{~cm}^{-1}$. FTIR spectrum of M5 was shown in Figure 6c. There is a shift in absorption band of $\mathrm{C}=\mathrm{O}$ stretching of carboxylic acid to lower value which observed at $1748 \mathrm{~cm}^{-1}$. On the other hand, the ${ }^{1} \mathrm{H}$ NMR spectrum of M5 in DMSO- $d_{6}$ revealed the signals at $\delta 1.4,1.7,2.6$ and $3.6 \mathrm{ppm}$. These were attributed to the two methylene (- $\left.\mathrm{CH}_{2}-\right)$ protons and two methine (-CH-) protons and 4.4 ppm for $\mathrm{OH}$ group in PVA/AAc copolymer moiety. The other protons in amine polymers which characteristic to pyrazol-H, benzene rings, imino and $\mathrm{NHSO}_{2}$ groups were appeared at $\delta 6.7,7.1,7.5-7.7,10.1$ and $11.3 \mathrm{ppm}$, respectively. 


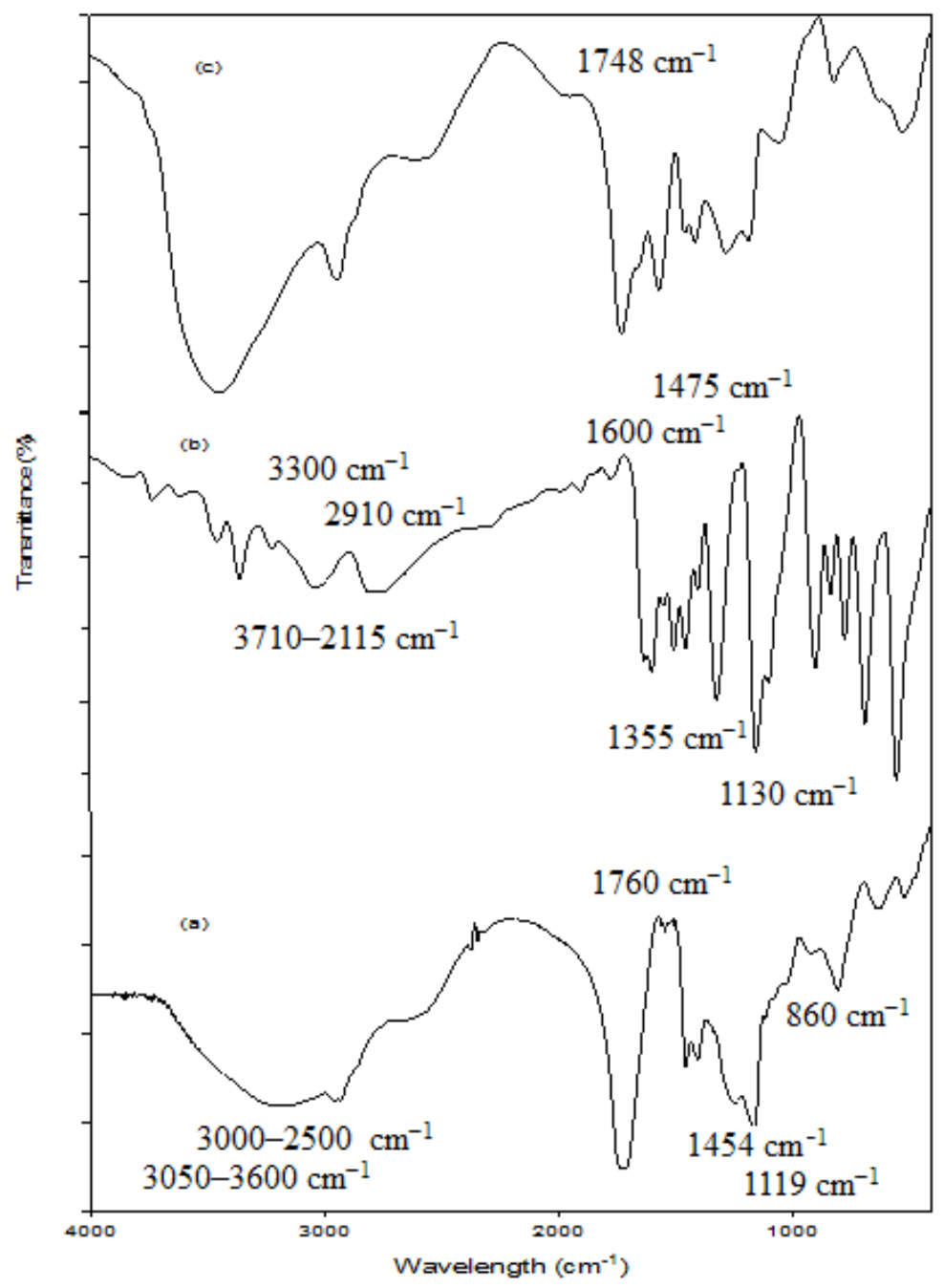

Figure 6. FT-IR spectra of (a) PVA/AAc hydrogel, (b) P5 and (c) M5.

FTIR spectrum of 4-amino- $N$-(4-methoxy-1,2,5-thiadiazol-3-yl) benzene sulfonamide (P6) was shown in Figure 7b. It showed a characteristic broad band at $3220 \mathrm{~cm}^{-1}$ that corresponds to $\mathrm{O}-\mathrm{H}$ stretched vibration. A very broad band corresponding showed to carboxyl groups has stretching frequency in the region 3000$2500 \mathrm{~cm}^{-1}$. The sharp band at $2910 \mathrm{~cm}^{-1}$ is due to the stretching vibration of backbone aliphatic $\mathrm{C}-\mathrm{H}$. The strong absorption peak at $1130 \mathrm{~cm}^{-1}$ has been assigned to the $\mathrm{C}-\mathrm{O}$ in stretching mode and the bands observed at $1355 \mathrm{~cm}^{-1}$ have been attributed to combination frequencies of $\mathrm{CH}-\mathrm{OH}$. The $\mathrm{C}=\mathrm{C}$ aromatic stretches appear in a pair of peaks and the other one at $1600 \mathrm{~cm}^{-1}$ and one at $1475 \mathrm{~cm}^{-1} . \mathrm{N}-\mathrm{H}$ stretching appeared at $3300 \mathrm{~cm}^{-1}$ and $\mathrm{C}-\mathrm{N}$ stretch occurred at $1300 \mathrm{~cm}^{-1}$ whereas, $\mathrm{S}=\mathrm{O}$ stretching appeared at $1400 \mathrm{~cm}^{-1}$. FTIR spectrum of PVA/AAc/P6 (M6) was shown in Figure 7c. There is a shift in absorption band of $\mathrm{C}=\mathrm{O}$ stretching of carboxylic acid to lower value which observed at $1748 \mathrm{~cm}^{-1}$. Finally, the structure of M6 was conformed by the ${ }^{1} \mathrm{H}$ NMR spectrum in DMSO- $d_{6}$ which revealed the presence of signals at $\delta=1.2$ and $1.5 \mathrm{ppm}$ characteristic for two methylene $\left(-\mathrm{CH}_{2}-\right)$ protons group with two signals at $\delta 2.7,3.8$ $\mathrm{ppm}$ characteristic for methine (-CH-) protons and 4.0, $4.5 \mathrm{ppm}$ for methoxy and hydroxyl groups in the product amine polymer, in addition to the signals at $\delta 7.6,7.7$, 10.3 and 11.2 ppm attributable to aromatic protons, imino and $\mathrm{NHSO}_{2}$ protons. 


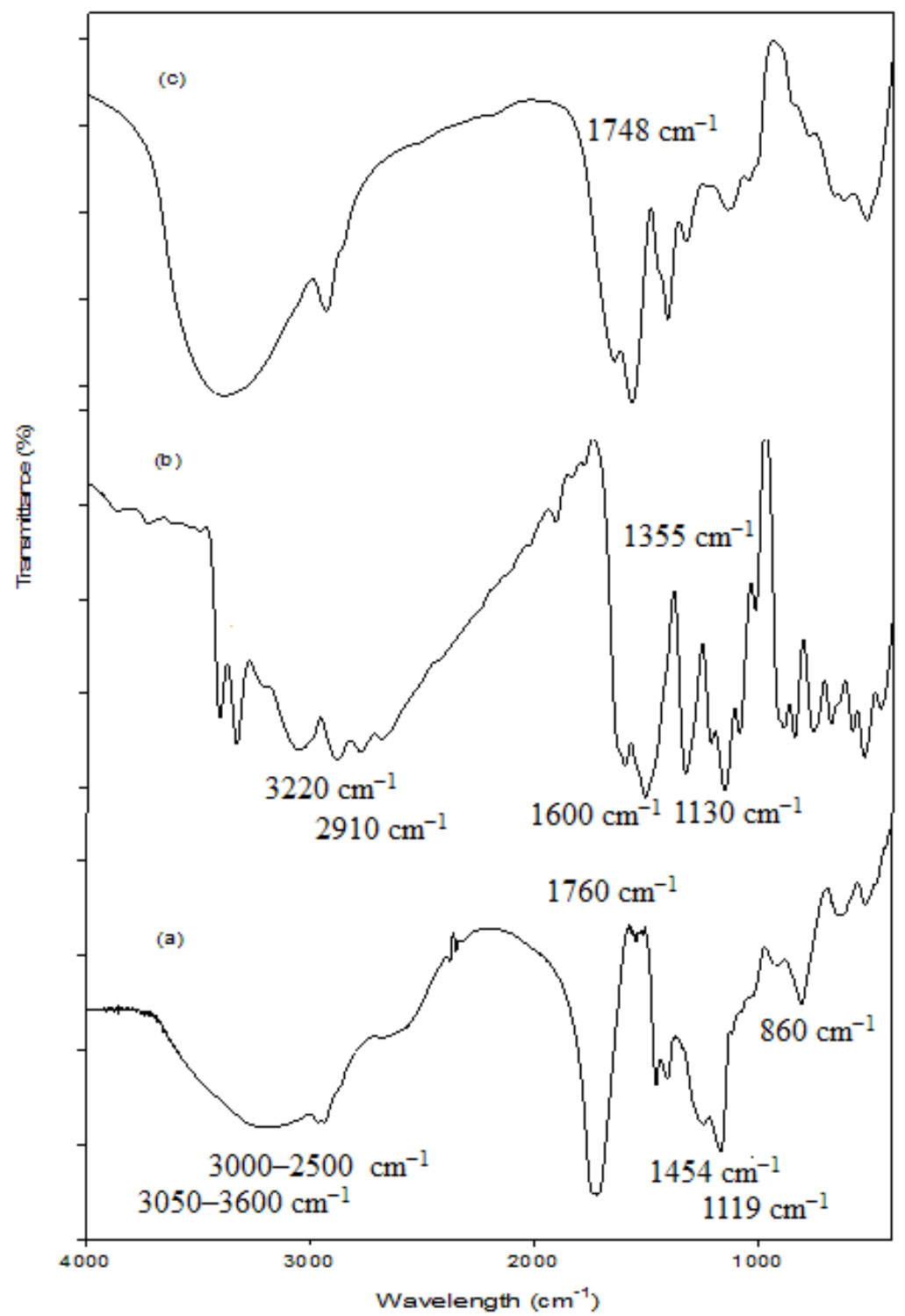

Figure 7. FT-IR spectra of (a) PVA/AAc hydrogel, (b) P6 and (c) M6.

\subsection{Swelling behavior}

The swelling behavior of hydrogel depends on the nature of polymer network such as the presence of hydrophilic groups, crosslinking density and elasticity of polymer networks, $\mathrm{pH}$ and temperature of the swelling medium (Abd El-Mohdy et al., 2006). As such, any variation of the PVA/AAc hydrogel network structure should directly influence its swelling behavior. The ionic charge content of PVA/AAc copolymer, which affects its swelling property, is related to the ratio between the PVA and AAc in the feed solution. Therefore, the swelling of PVA/AAc copolymers of different PVA: AAc compositions, was investigated at different irradiation doses and the results are shown in Figure 8. It is clear that swelling increased with increasing AAc content in the PVA/AAc copolymer and lowered irradiation doses, reaching its maximum at PVA: AAc composition; 50:50 wt $\%$. The results were discussed as follows: the swelling increased with enhanced AAc content due to the hydrophilic 
characters of AAc as well as $\mathrm{COOH}$ groups that enhance the water uptake (Abd ElMohdy and Abd El-Rehim 2009).

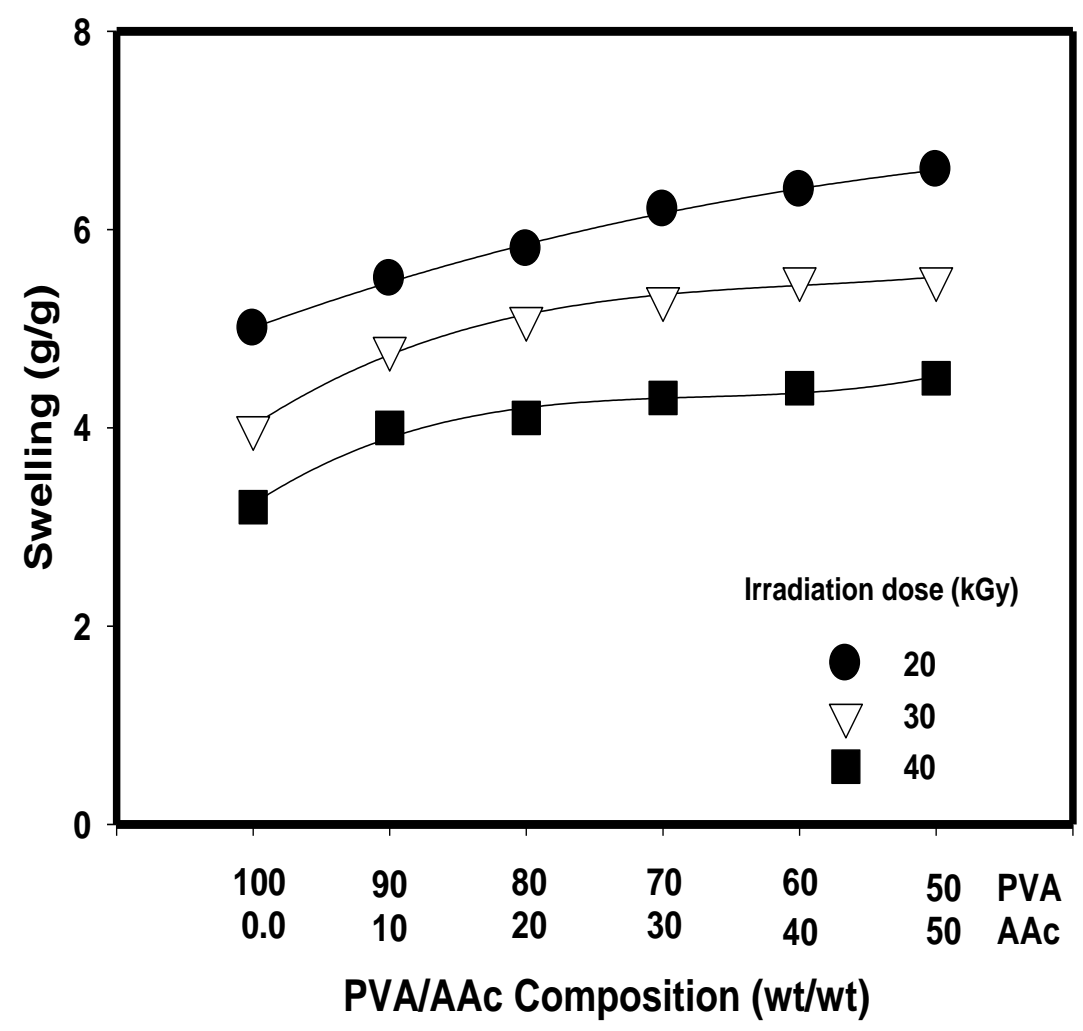

Figure 8. Effect of various PVA : AAc compositions on the equilibrium swelling of PVA/AAc hydrogels at different irradiation doses.

Figure (9) shows the swelling of the different amine-based PVA/AAc hydrogels (M1-M6) in compared with neat PVA/AAc. It is cleared that M1 and M2 have high swelling values in compared with PVA/AAc hydrogel and the other aminepolymeric compounds. This may be due to the presence of hydrophilic groups such as $\mathrm{COOH}$ in $\mathbf{M 1}$ and $\mathrm{NH}_{2}$ in $\mathbf{M 2}$. The swelling of M3-M6 reduced in compared with PVA/AAc hydrogel due to absence of hydrophilic groups. The swelling characters of prepared polymeric compounds were supported by their morphological structure as well as hydrogel surfaces which were shown in Figure 10. One of the most important properties that must be considered is hydrogel microstructure morphologies. The morphological structure of hydrogels is identified by scanning electron microscopy (SEM). SEM can provide information on the surface of a material. It was used here to detect the topography of PVA/AAc and PVA/AAc/amines hydrogel surfaces. The SEM 
photographs of hydrogel surfaces, which prepared at irradiation dose; $30 \mathrm{kGy}$ showed that the porous structure and pore size increased in case of amine polymers in compared with neat PVA/AAc. The images verify that PVA/AAc polymers have porous structure. It has been observed that PVA/AAc has smooth and homogeneous morphology whereas it has structural heterogeneity with interaction of amine compounds to it. It is supposed that these pores are the regions of water permeation and interaction sites of external stimuli with the hydrophilic groups in the PVA/AAc and amine compounds. Therefore, the porous structure is the predominant reason for the higher swelling ratios (Abd ElMohdy 2007).

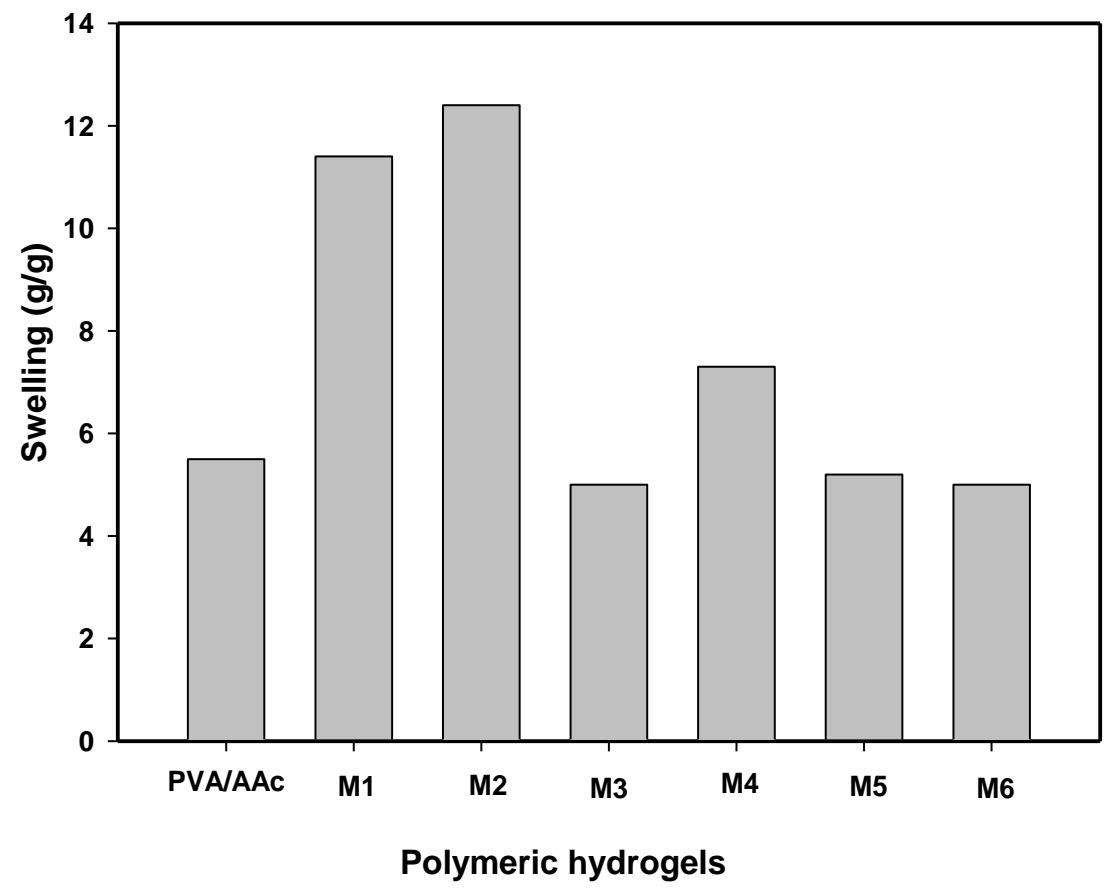

Figure 9. Equilibrium swelling of different PVA/AAc/amines (M1-M6) in compared with neat PVA/AAc. 


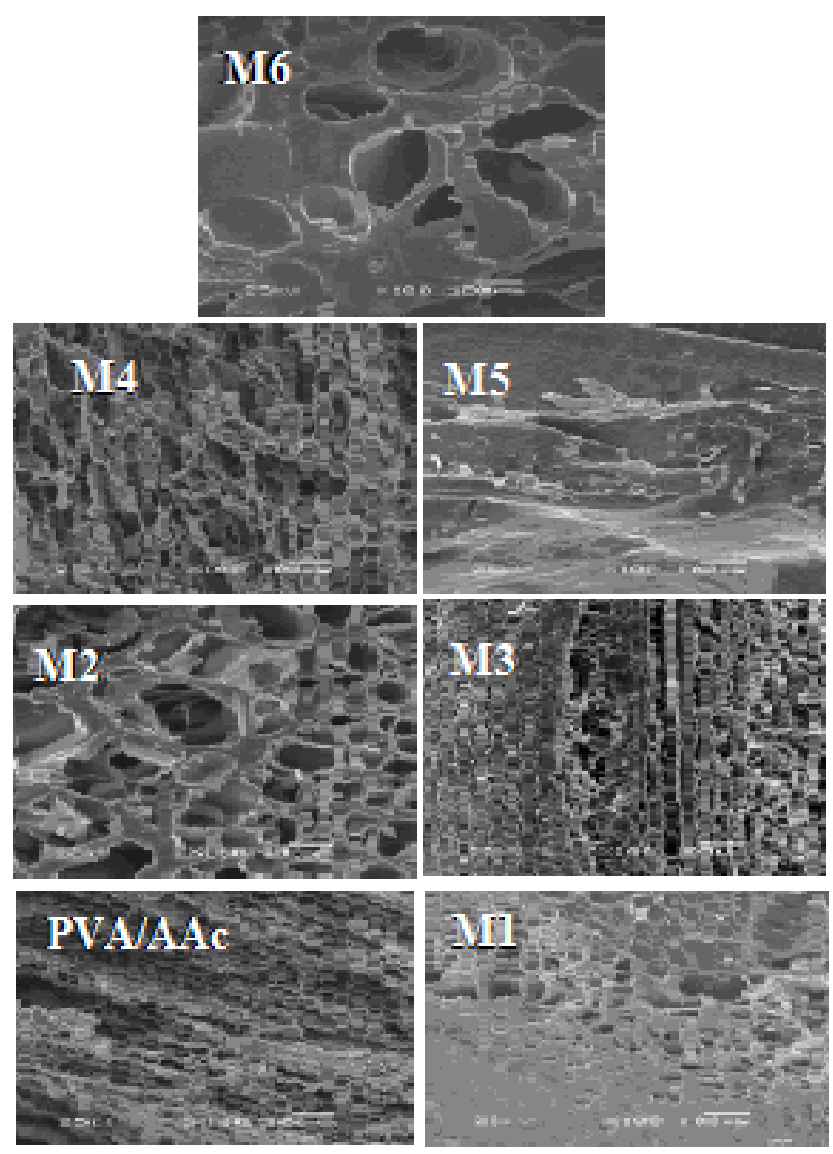

Figure 10. SEM images for PVA/AAc and PVA/AAc/amines (M1-M6).

\section{Thermal properties}

\section{Thermogravimetric analysis (TGA).}

TGA curves of different PVA/AAc/amines (M1-M6) hydrogels in compared with neat PVA/AAc hydrogel in nitrogen atmosphere are shown in Fig. 11. It was cleared that, the prepared polymers had three decomposition regions. The first region started from $50^{\circ} \mathrm{C}$ and ended at about $200^{\circ} \mathrm{C}$ with loss in weight about $5 \%$; in case of PVA/AAc whereas, it was about $5-10 \%$ for PVA/AAc/amine polymers. This loss may be due to the evaporation of the moisture and untreated amine or trapped monomer present in the sample. At the second region which started after $200^{\circ} \mathrm{C}$, the weight loss was increased by increasing the heating temperature. This loss in weight was attributed to the actual pyrolysis by minor decomposition reaction. The third decomposition region for PVA/AAc which gave the suddenly major decomposition reaction, started at $335^{\circ} \mathrm{C}$ and finished at $370^{\circ} \mathrm{C}$ with weight loss from $60-100$ wt. $\%$ whereas the decomposition of other amine polymers delayed to $600^{\circ} \mathrm{C}$. The decomposition took place due to occurring depolymerization with formation of $\mathrm{H}_{2} \mathrm{O}, \mathrm{CO}, \mathrm{CO}_{2}$ and $\mathrm{CH}_{4}$. 


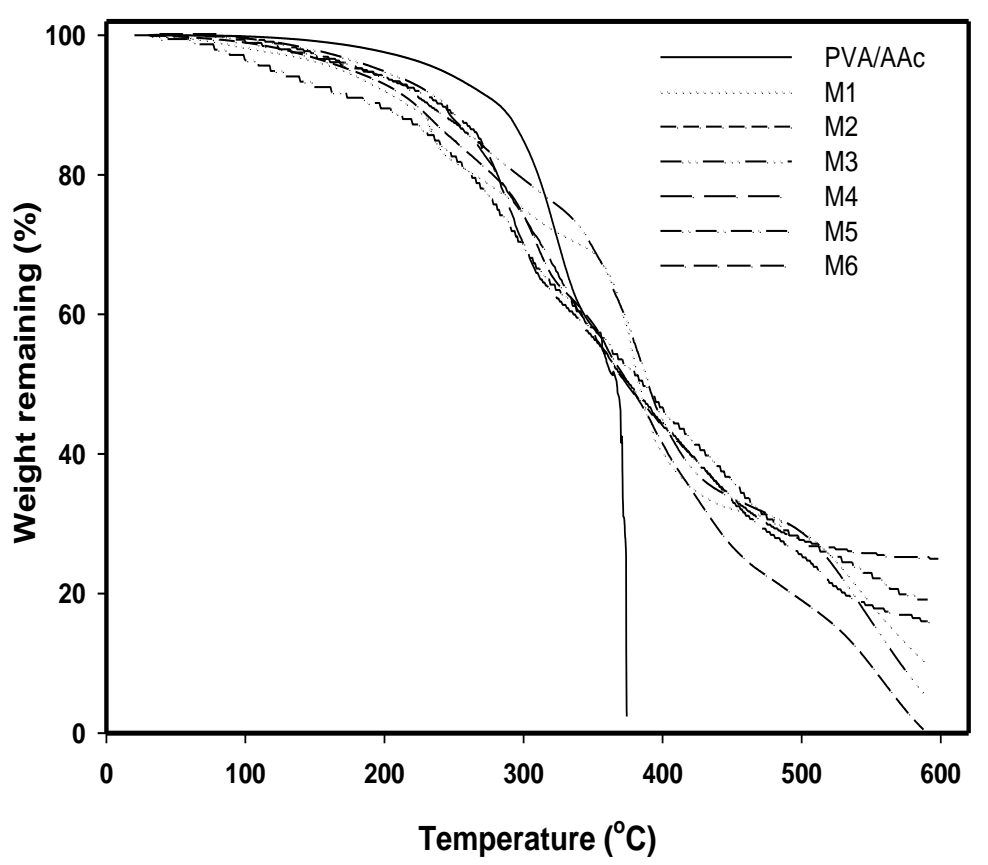

Figure 11: Thermo-gravimetric analysis of PVA/AAc hydrogels and modified hydrogels.

\subsubsection{Differential scanning calorimetry (DSC)}

Due to the high percentage of water content in the hydrogel samples, DSC scans failed to detect any thermal transitions of the polymer present in the swollen polymers. Therefore all samples were dried at $37^{\circ} \mathrm{C}$ for $48 \mathrm{~h}$ before testing. Fig. 12 shows the thermal parameters of both PVA/AAc and amine-modified PVA/AAc compounds. They are determined by measuring the change in thermal properties such as melting temperature $(\mathrm{Tm})$ and heat of fusion $(\Delta H)$ of these polymers using DSC. The thermal diagram of prepared hydrogels showed that $T m$ of amine-modified polymers reduced to lower values in compared with PVA/AAc whereas $\Delta H$ values were changed to different values, Table 1 . This decrease in melt temperature is possibly due to morphological changes within the polymer matrix. These may involve changes in the size of the crystallites and the degree of crystallinity. Also, this occurred due to the interaction that occurred between PVA/AAc hydrogel and amine compounds. 


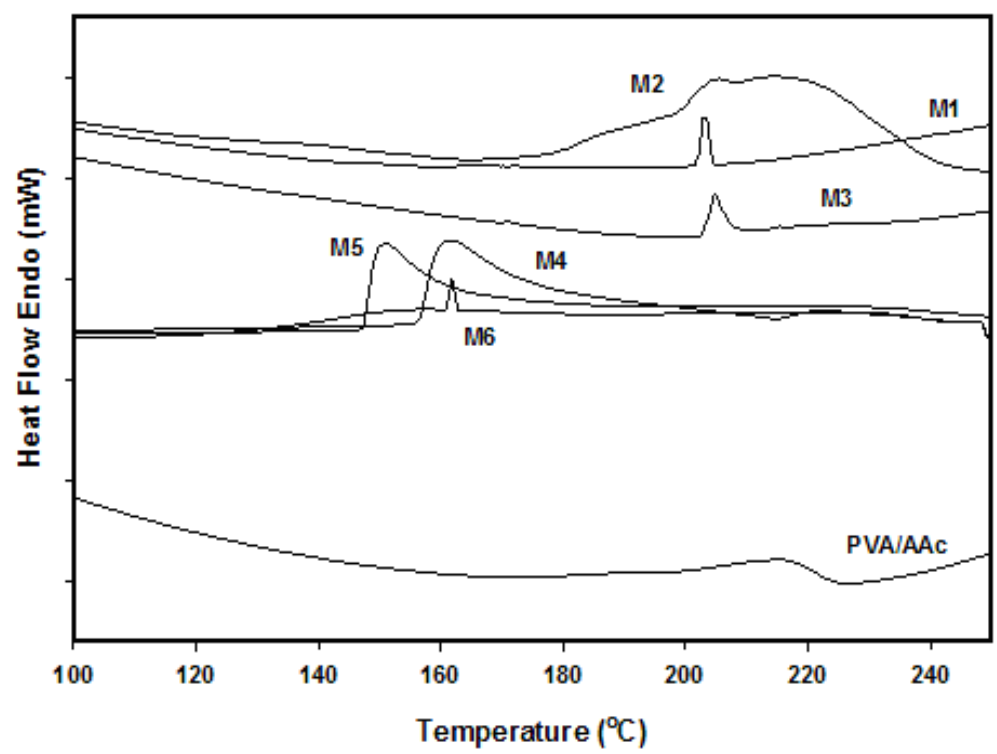

Figure 12. DSC analysis of PVA/AAc hydrogels and modified hydrogels.

Table 1. Thermal parameters for PVA/AAc and PVA/AAc/amines hydrogels.

\begin{tabular}{|c|c|c|}
\hline \multirow{2}{*}{ Hydrogels } & \multicolumn{2}{|c|}{ Thermal parameters } \\
\cline { 2 - 3 } & \multirow{2}{|c|}{ Tm $\left({ }^{\circ} \mathrm{C}\right)$} & $\Delta \mathrm{H}_{\mathrm{m}}$ \\
& & $(\mathrm{J} / \mathrm{g})$ \\
& & \\
\hline PVA/AAc & 215.5 & 17.6 \\
\hline M1 & 203.1 & 0.065 \\
\hline M2 & 214.6 & 160.1 \\
\hline M3 & 204.6 & 8.2 \\
\hline M4 & 162 & 96.8 \\
\hline M5 & 151 & 78.2 \\
\hline M6 & 161.5 & 106.5 \\
\hline
\end{tabular}

\section{UV-vis spectroscopy}

To prove the formation of the amine-modified PVA/AAc polymers in compared with PVA/AAc gel, UV-vis absorption studies were carried out. With trapping of amine compounds with PVA/AAc gel, the absorbance peaks increased in compared with neat 
gel. As shown in Fig.13, both the intensity and the value of absorbance changed with differing in the structure of polymeric gels. On the other hand, plasmon absorption increments in the UV-vis spectra represent the changes in the structure of polymeric gels.

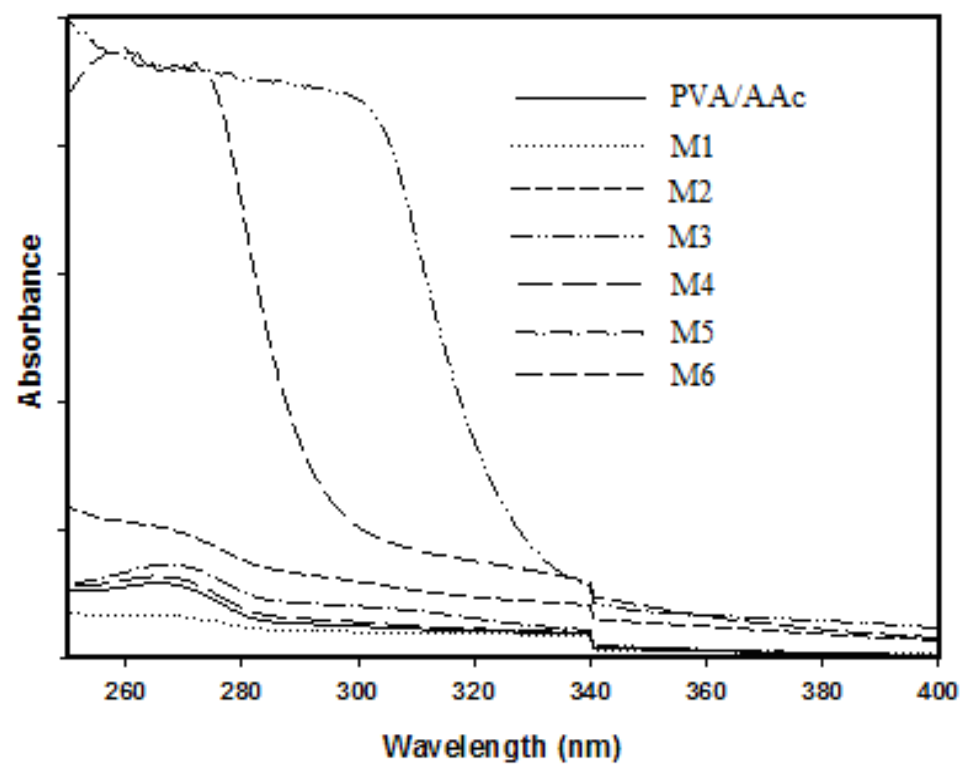

Figure 13 UV-vis spectroscopy of PVA/AAc hydrogels and modified hydrogels.

\section{Antimicrobial activity}

The biological activity of the seven investigated hydrogels (PVA/AAc and PVA/AAc-amines; M1-M6) was tested against a representative number of pathogenic organisms. Test fungi included, Aspergillus fumigatus, Geotrichum candidum, Candida albicans and Syncephalastrum racemosum. Test bacteria included, Staphylococcus aureus and Bacillus subtilis as gram positive bacteria, whereas Pseudomonas aeruginoca and Escherichia coli as gram negative bacteria. It is known that the structural variables that alter the properties of polymers would affect their biological activity against microorganisms (Abd El-Mohdy and Ghanem 2009). The properties of polymeric materials would be influenced by the chemical nature, molecular weight and configuration structure of the polymer. Therefore, the effect of chemical composition and molecular weight of PVA/AAc copolymers as well as the presence of pharmacological active moieties such as sulpha-drugs introduced to PVA/AAc copolymers on their activity against pathogenic microorganisms, were investigated. Clotrimazole and Itraconzole were used as references to evaluate the potency of the tested compounds under the same conditions. Zones of inhibition were determined for compounds PVA/AAc, M1, M2, M3, M4, M5 and M6, the results of antifungal and antibacterial activities were summarized in both Table 2, and Table 3, respectively. The results obtained showed that, as the amine compounds entrapped in the polymeric matrix, their biological activity against the investigated pathogenic microorganisms increases. 
Table 2. Antifungal activity of the tested hydrogels.

\begin{tabular}{|c|c|c|c|c|}
\hline \multirow{2}{*}{$\begin{array}{c}\text { Compound } \\
\text { No. }\end{array}$} & $\begin{array}{c}\text { Inhibition zone diameter (mm) } \\
\text { fumigatus } \\
\text { (RCMB } \\
\text { 002003) }\end{array}$ & $\begin{array}{c}\text { Geotrichum } \\
\text { candidum } \\
\text { (RCMB } \\
\text { 052006) }\end{array}$ & $\begin{array}{c}\text { Candida } \\
\text { albicans } \\
\text { (RCMB } \\
\text { 005002) }\end{array}$ & $\begin{array}{c}\text { Syncephalastrum } \\
\text { racemosum } \\
\text { (RCMB 005003) }\end{array}$ \\
\hline PVA/AAc & $11.2 \pm 0.03$ & $13.4 \pm 0.04$ & $\mathbf{1 0 . 2} \pm \mathbf{0 . 0 3}$ & NA \\
\hline M1 & $15.2 \pm 0.06$ & $18.4 \pm 0.04$ & $15.4 \pm 0.1$ & NA \\
\hline M2 & NA & NA & NA & NA \\
\hline M3 & $19.3 \pm 0.03$ & $17.2 \pm 0.07$ & $16.4 \pm 0.08$ & $16.8 \pm 0.05$ \\
\hline M4 & $21.6 \pm 0.09$ & $18.6 \pm 0.08$ & $17.3 \pm 0.02$ & $18.9 \pm 0.07$ \\
\hline M5 & $14.2 \pm 0.08$ & $21.4 \pm 0.05$ & $17.8 \pm 0.03$ & $20.1 \pm 0.07$ \\
\hline M6 & $28 \pm 0.05$ & $27 \pm 0.10$ & $26 \pm 0.02$ & $22 \pm 0.09$ \\
\hline Itraconazole & $26 \pm 0.10$ & $23 \pm 0.03$ & $18 \pm 0.10$ & $20 \pm 0.20$ \\
\hline Clotrimazole & 26 & & NA \\
\hline
\end{tabular}

Mean zone of inhibition in $\mathrm{mm} \pm$ Standard deviation beyond well diameter (6 $\mathrm{mm}$ ) produced on a range of environmental and clinically pathogenic microorganisms using $(10 \mathrm{mg} / \mathrm{ml})$ concentration of tested samples and standard using $(30 \mathrm{mg} / \mathrm{ml})$.

The test was done using the diffusion agar technique, Well diameter: $6.0 \mathrm{~mm}(100 \mu \mathrm{l}$ was tested).

NA: No activity, data are expressed in the form of mean \pm SD 
Table 3. Antibacterial activity of the tested hydrogels.

\begin{tabular}{|c|c|c|c|c|}
\hline \multirow[b]{3}{*}{ Compound No. } & \multicolumn{4}{|c|}{ Inhibition zone diameter (mm) } \\
\hline & \multicolumn{2}{|c|}{ Gram positive bacteria } & \multicolumn{2}{|c|}{ Gram negative bacteria } \\
\hline & $\begin{array}{c}\text { Staphylococcus } \\
\text { aureus } \\
\text { (RCMB } \\
\text { 000106) }\end{array}$ & $\begin{array}{l}\text { Bacillis } \\
\text { subtilis } \\
\text { (RCMB } \\
\text { 000107) }\end{array}$ & $\begin{array}{c}\text { Pseudomonas } \\
\text { aeruginosa } \\
\text { (RCMB } \\
\text { 000102) }\end{array}$ & $\begin{array}{c}\text { Escherichia } \\
\text { coli } \\
\text { (RCMB } \\
\text { 000103) }\end{array}$ \\
\hline PVA/AAc & $14.4 \pm 0.50$ & $16.4 \pm 0.10$ & NA & NA \\
\hline M1 & $17.2 \pm 0.01$ & $18.3 \pm 0.03$ & $11.4 \pm 0.09$ & $9.2 \pm 0.02$ \\
\hline M2 & $13.2 \pm 0.01$ & $14.3 \pm 0.03$ & NA & NA \\
\hline M3 & $15.2 \pm 0.08$ & $13.5 \pm 0.2$ & NA & NA \\
\hline M4 & $21.6 \pm 0.09$ & $23.9 \pm 0.07$ & $16.9 \pm 0.02$ & $18.7 \pm 0.03$ \\
\hline M5 & $23.4 \pm 0.06$ & $25.7 \pm 0.07$ & $18.2 \pm 0.06$ & $21.3 \pm 0.08$ \\
\hline M6 & $26.4 \pm 0.08$ & $27.1 \pm 0.06$ & $21.2 \pm 0.06$ & $24.9 \pm 0.08$ \\
\hline Penicillin $G$ & $29.4 \pm 0.08$ & $32.5 \pm 0.05$ & $28.3 \pm 0.10$ & $33.5 \pm 0.07$ \\
\hline Streptomycin & $25.0 \pm 0.20$ & $29.0 \pm 0.04$ & $24.0 \pm 0.10$ & $25.0 \pm 0.03$ \\
\hline
\end{tabular}

Mean zone of inhibition in $\mathrm{mm} \pm$ Standard deviation beyond well diameter $(6$ mm) produced on a range of environmental and clinically pathogenic microorganisms using $(10 \mathrm{mg} / \mathrm{ml})$ concentration of tested samples and standard using $(30 \mathrm{mg} / \mathrm{ml})$.

The test was done using the diffusion agar technique, Well diameter: $6.0 \mathrm{~mm}$ (100 $\mu$ l was tested).

NA: No activity, data are expressed in the form of mean \pm SD

\section{Conclusions}

PVA/AAc hydrogels that prepared by using $\gamma$-irradiation, were modified to produce new PVA/AAc/amines. The swelling of gels was varied with changes in PVA:AAc contents as well as amine structure. Swelling of prepared polymers increased with AAc content. Amine-modified polymers, M1 and M2, have high swelling values in compared with PVA/AAc hydrogel and the other amine-polymeric compounds, whereas the swelling of M3-M6 reduced due to absence of hydrophilic groups. PVA/AAc has smooth and homogeneous morphology whereas; it has structural heterogeneity at interaction with amine compounds. DSC-TGA scans proved that the 
modified PVA/AAc hydrogels are thermally less stable than unmodified one. Biological activity of synthesized amine-modified PVA/AAc exhibited higher promising biological activities and can be used in medical applications.

\section{REFERENCES}

Abd El-Mohdy H. L., Hegazy E. A., Abd El-Rehim H. A. (2006): Characterization of Starch/Acrylic Acid Super-Absorbent Hydrogels Prepared by Ionizing Radiation, J. Macromol. Sci., Part A: Pure Appl. Chem., 43, 1051-1060.

Abd El-Mohdy H. L. (2012): Controlled Release of Testosterone Propionate Based on Poly N-Vinyl Pyrrolidone/2-Acrylamido-2-Methyl-1-Propanesulfonic Acid Hydrogels Prepared by Ionizing Radiation, J. Polym. Res., 19, 9931-999.

Abd El-Mohdy H. L. (2007): Water Sorption Behavior of CMC/PAM Hydrogels Prepared by $\gamma$-Irradiation and Release of Potassium Nitrate as Agrochemical. React. Funct. Polym., 67, 1094-1100.

Abd El-Mohdy H.L., Abd El-Rehim H.A. (2008): Radiation Induced Kappa Carrageenan/Acrylic Acid Graft-Copolymers and Their Application as Catalytic Reagent for Sucrose Hydrolysis, Chem. Engin. J., 145, 154-159.

Abd El-Mohdy H.L., Abd El-Rehim H.A. (2009): Radiation Synthesis of KappaCrrageenan/Acrylamide Graft Copolymers as Superabsorbents and Their Possible Applications, J. Polym. Res., 16, 63-71.

Abd El-Mohdy H.L., Ghanem S. (2009): Biodegradability, Antimicrobial Activity and Properties of PVA/PVP Hydrogels Prepared by $\gamma$-Irradiation, J. Polym. Res., $16,1-10$.

Abdel-Bary E. M., Moawad, E. B., Helaly F. M., Abdelaal M. Y., Rashed W. F. (1997): Synthesis of Some Heterocyclic Compounds and Their Ability for Metal Uptake. Polym. Degrad. Stab., 57, 283-290.

Aziz M.A., Cabral J.D., Brooks H.J., Moratti S.C., Hanton L.R. (2012): Antimicrobial Properties of A Chitosan Dextran-Based Hydrogel for Surgical Use, Antimicrob. Agents Chemother., 56, 280-287.

Benamer S., Mahlous M., Boukrif A., Mansouri B., Youcef S.L. (2006): Synthesis and Characterisation of Hydrogels Based on Poly(Vinyl Pyrrolidone), Nucl. Instrum. Methods Phys. Res., 248, 284-290.

Das N., Bera T., Mukherjee A. (2012): Biomaterial Hydrogels for Different Biomedical Applications, Int. J. Pharm. Bio. Sci., 3, 586-595.

Izaoumen N., Bouchta D., Zejli H., El Kaoutit M., Stalcup A. M. Temsamani K. R. (2005): Temsamani, Chemical Modification of Polymers and Their Applications, Talanta, 66, 111-118.

Jayachandran V., Rangasamy J., Annapoorna M., Ira B., Se-Kwon K. (2014): Antimicrobial Activity of Chitosan-Carbon Nanotube Hydrogels, Materials, 7, 3946-3955. 
Pernot H., Baumert M., Court, F., Leibler, L. (2002): Functional Polymers as A Method for Solvent-Free Preparation of Block Copolymers, Nature Mater., 1, 54-62.

Sanghi R., Verma P. (2009): Characterization of polymers, Bioresource. Technolgy, $100,501$.

Sarhan A. A., El-Shehawy A. A., Abdelaal M. Y. (2002): Utilization of Macroporous Polymer Containing Phenylboronic Acid Groups in the solid- phase synthesis. React. Funct. Polym., 50, 139-147.

Yin Z., Koulic C., Pagnoulle C., Jerome R. (2003): Probing of the Reaction Progress at A PMMA/PS Interface by Using Anthracene-Labeled Reactive PS Chains. Langmuir, 19, 453-460.

Zhang Y.X., Wu F.P., Li M.Z., Wang E.J. (2005): pH Switching On-Off Semi-IPN Hydrogel Based on Cross-Linked Poly(Acrylamide-co-Acrylic Acid) and Linear Polyallyamine, Polymer, 46, 7695-7700.

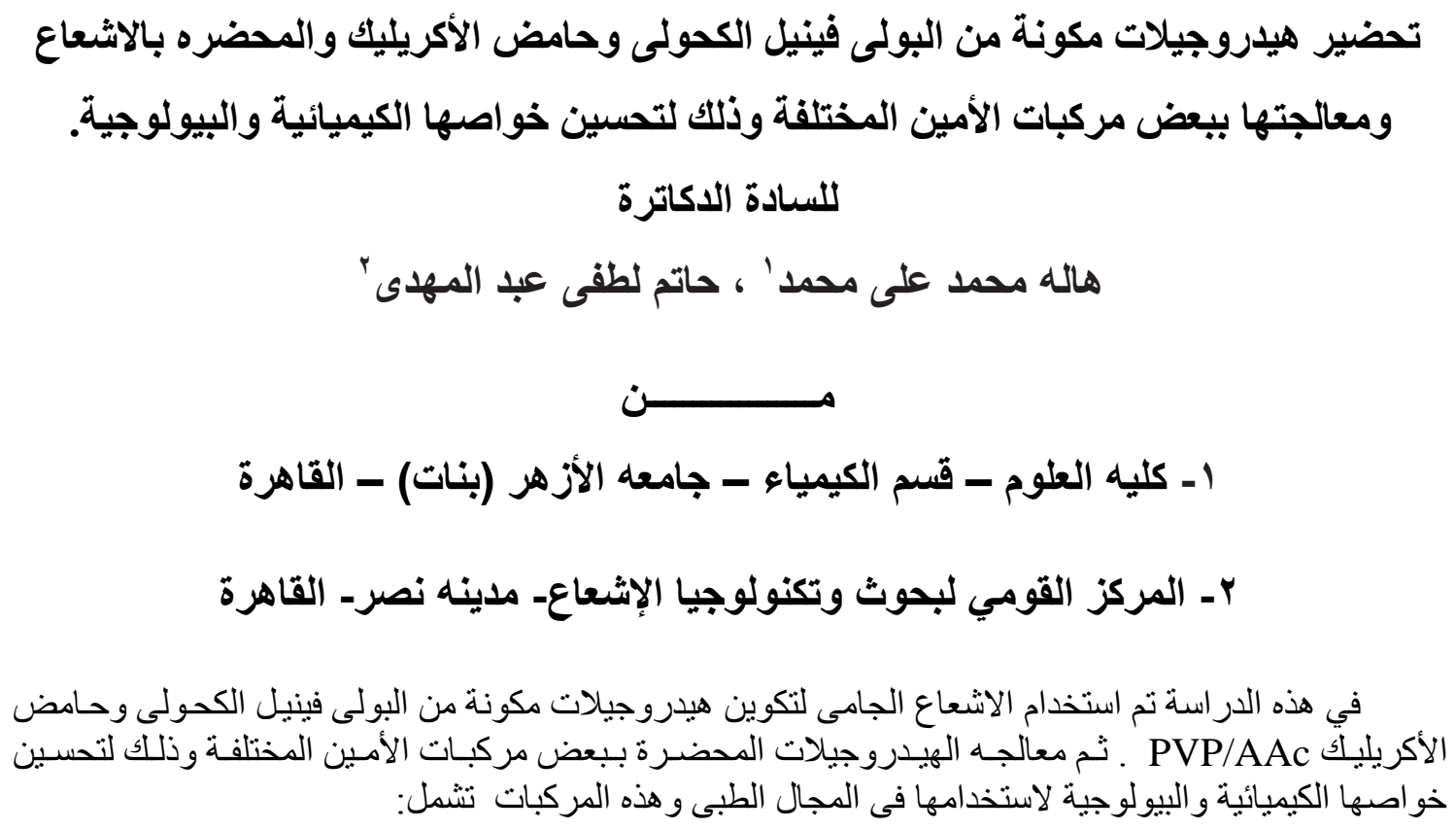

L-tyrosine (P1), 1,2-Diaminopropane (P2), 2-Aminoantipyrine (P3), 4-Amino-N-(1phenyl-1H-pyrazol-5-yl) benzenesulfonamide (P4), 4-Amino-N-(4-methoxy-1,2,5thiadiazol-3-yl) benzenesulfonamide (P5), and Thiazol-2-amine (P6).

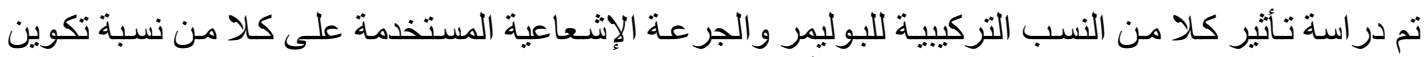

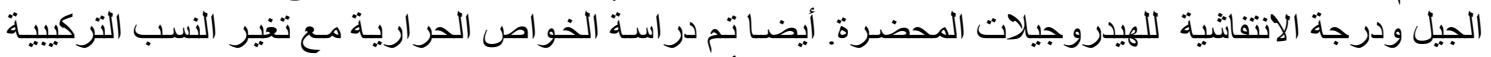

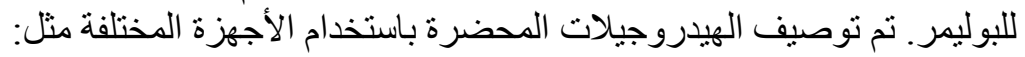

FT-IR, NMR spectroscopy \&, DSC and TGA

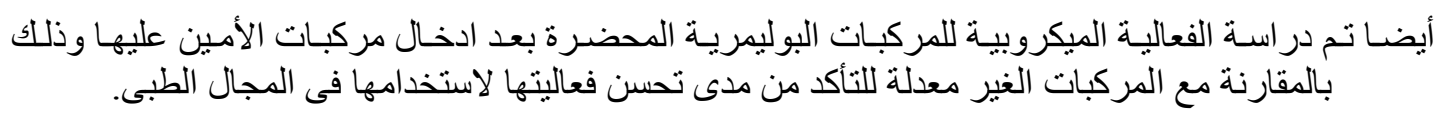

